\title{
Does a Multi-Dimensional Concept of Health Include Spirituality? Analysis of Japan Health Science Council's Discussionson WHO’s ‘Definition of Health’ (1998)
}

\author{
Mas ako Nagase \\ Faculty of Health Care and Nursing, Juntendo University, Chiba, 279-0023, Japan
}

\begin{abstract}
The Health Science Council of Japan proposed to include the term 'spirituality' in WHO's 'definition of health' over three meetings. However, no consensus on the proposal was achieved. This study uses the minutes of the meetings to explore the members' implicit understanding of 'health', varied interpretations of 'spirituality', and reservations against the inclusion of 'spirituality' in the official definition of health. By analy zing the Japanese perspective on the subject, this study seeks to contribute to the conceptual definition of 'health' and elucidate the challenges involved in incorporating 'spirituality' as a dimension of health in the field of contemporary med ical care.
\end{abstract}

Keywords WHO, Defin ition of Health, Spirituality, the Health Science Council of the Former Ministry of Health and Welfare

\section{Introduction}

In 1999, the field of Japanese medical care witnessed a sharp increase in the number of academic publications on spirituality[1]. Possibly, the increased focus on spirituality stemmed from the proposal, submitted between 1998 and 1999, to revise the 'definition of health' by including the aspect of spirituality in the preamble to the World Health Organization (WHO)'s Charter. A revision in the definition was proposed at the 101st session of the WHO Executive Board by the WHO Regional Office for the Eastern Mediterranean, which included members from Islamic member countries. The proposal sought to modify the definition of health by adding the underlined word as follows: 'Health is a dynamic state of complete physical, mental, spiritual, and social well-being and not merely the absence of disease or infirmity' [2].

Although many Japanese people participate in religious ceremonies that include weddings, births, funerals and New Year prayers, there is a little sense of affiliation to any specific religious organization.Accordingly, there are many who consider themselves 'not religious', and according to a survey conducted by a leading Japanese newspaper[3], 76\% 'do not believe in any religion'. On the other hand, 94\% have a deep feeling of reverence towards their ancestors and $56 \%$ 'sense something in nature that surpasses the power of

* Corresponding author:

mnagase@juntendo.ac.jp (Masako Nagase)

Published online at http://journal.sapub.org/ijas

Copyright (C) 2012 Scientific \& Academic Publishing. All Rights Reserved human beings'. While keeping a distance from any specific group, Japanese people tend to consider it important to have a deep respect for deities or powers that are beyond human understanding.

The proposed definition differed from the orig inal in two aspects. First, the concept of 'health' was not identified as an individual's state of being healthy or ill but as a continuous and dynamic condition. Second, a spiritual dimension was added to the physical, mental, and social dimensions of health. The proposal was incorporated into the agenda of the 52nd World Health Assembly (WHA52) with 22 votes in favor, none against, and eight spoilt ballots.

WHA52 was held from 17-25 May, 1999; however, the proposal to revise the WHO's 'defin ition of health' was not discussed. Unfortunately, in the subcommittee deliberations held prior to the General Assembly, it was decided that deliberations would not be held during the General Assembly[2]. Eiichi Nakamura, a Japanese delegate attending the subcommittee meeting, was among those opposed to having deliberations at the WHA52 in favor ensuring more time for discussions ([4],[5]). Nakamura's comments were considered reflective of the views of the Health Science Council of the Former Min istry of Health and Welfare in Japan, the only official body at the central government level to have held deliberations on the proposal to amend WHO's defin ition of health, within Japan.

These deliberations have been the subject of a couple of studies on healthcare([6],[7]). Both the studies confirm that the translation of the term 'spirituality' represented a problem at the council meeting. Tanatsugu added that the members in the deliberation council ultimately failed to 
arrive at a consensus on the differences between the words 'mental' and 'spiritual'. This lack of consensus is said to have contributed to Nakamura's stand at the WHA52 subcommittee.

To date, there only exists a tacit acceptance of the notion of spiritual well-being within the conceptual dimensions of 'health' in the field of nursing and welfare in Japan. The true notion of spirituality and the challenges of incorporating it in the official definitions of health within contemporary medical care are yet to be fully explored. This study attempts to address this gap through a retrospective analys is of the reasons that contributed to the disagreement among committee members of the Health Science Council over the inclusion of spirituality in the definition of health. Unlike earlier studies that summarized the views of the officials of Health Science Council, this study seeks to provide a detailed review of the proceedings by using the minutes of the meeting as investigative data. It answers questions such as who were the attendees at the deliberation council, what were their views, and how they were put forward and, more importantly, what were the themes of conflict. By analyzing Japan's perspective on health and spirituality through the minutes of the Health Science Council's deliberations, this study sheds light on the current challenges in defining health as well the relationship between modern medicine and spirituality.

\section{Methods}

Table 1. Total number of menbers, their areas of expertise and their distribution across the three deliberation committee meeting (excludingds the chairperson)

\begin{tabular}{|c|c|c|c|c|}
\hline Domain of expertise & $\begin{array}{l}\text { Number of } \\
\text { members }\end{array}$ & $\begin{array}{l}\text { 6th general } \\
\text { meeting }\end{array}$ & $\begin{array}{c}14 \mathrm{th} \\
\text { departmental } \\
\text { meeting }\end{array}$ & $\begin{array}{c}15 \text { th } \\
\text { departmental } \\
\text { meeting }\end{array}$ \\
\hline \multicolumn{5}{|c|}{ Natural sciences } \\
\hline Medical science & 13 & 5 & 9 & 7 \\
\hline Pharmacology & 2 & 2 & & \\
\hline $\begin{array}{l}\text { Molecular biology/ } \\
\text { molecular genetics }\end{array}$ & 1 & & 1 & \\
\hline Bionics & 1 & 1 & & \\
\hline Science journalism & 1 & 1 & & 1 \\
\hline \multicolumn{5}{|c|}{ Non-life sciences } \\
\hline Bioethics & 2 & 1 & 2 & 1 \\
\hline Author & 1 & 1 & & \\
\hline $\begin{array}{c}\text { Total } \\
\text { per meeting }\end{array}$ & & 11 & 12 & 9 \\
\hline
\end{tabular}

As mentioned earlier, the minutes of the meeting of the Health Science Council of the Former Ministry of Health and Welfare that discussed the proposal to add spirituality to WHO's 'definition of health' were analyzed. Specifically, these minutes included records of three meetings: A. The 6th general meeting of the Health Science Council (March 19, 1999), B. The 14th meeting of the Health Science Council's Research and Planning Committee (April 12, 1999), and C.The 15th meeting of the Health Science Council's Research and Planning Committee (April 19, 1999). The total number of attendees at each meeting and their domains of expertise are listed in Table 1. Excluding the Chairpers on and overlapping participants, the number of committee members at each meeting was 21 . Most of the attendees were experts from the field of natural sciences, while three belonged to non-science disciplines. Throughout the three meetings, there were a total of 27 attendees - more than $80 \%$ of the whole members. One of these members, who was an author, stated she was a Christian, but the religion of other members was unknown.

The reasons for disagreement on the issue of including spiritual dimension in the 'definition of health' are examined from two perspectives. The first explores the framework that governed the committee's discussions of the term 'health'. The second perspective investigates discussions related to how 'health' should be defined using this framework as an implicit premise and whether or not spirituality should be included in the WHO's 'definition of health'. 
In line with the standard methods of qualitative analysis ([8],[9]), the recorded minutes were carefully interpreted, keeping in mind the perspectives of analysis. That is, by contextualizing the key points raised by each committee member within the scope of the analysis, the material was divided into themes. The minutes of all the three meetings were subjected to this process of interpretation. Existing themes were compared and contrasted with new data to continuously refine the interpretations. It must be mentioned here that the council members did not follow a question-and-answer approach to express their opinions on the proposal to add spirituality to WHO's 'definition of health'. Thus, for a complete understanding of the motivations behind their opinions, this study not only considers the actual words spoken by the council members but also the before-and-after contexts in which these comments were made.

Of the three meeting records, the minutes of Meeting B contained most of the discussions relevant to the subject of amending WHO's definition of health. It is likely that the presence of two members from the field of bioethics at Meeting $B$ enabled a more detailed examination of the concept of spirituality. At Meeting A, committee members were only invited to share their opinions on the proposal, whereas, at Meeting $\mathrm{C}$, which was held a week after Meeting $\mathrm{B}$, the proceedings did not proceed beyond a call for new ideas or opinions on the matter.

\section{Result}

\subsection{Framework for Discussing 'Health'}

The framework or the implicit premise of the discussions reflected in the council members' comments seemed to recognize human existence to belong to the realms of 'nature' and 'culture'. This view of human existence, characterized by the dichotomy of 'nature' and 'culture', is consistent with the outlook of modern and Western societies, as highlighted by Latour[10]. According to the modern view, 'nature' represents the objective world, and is also the subject of scientific study, such as medical science. In relation to human existence, it refers to the physical and mental faculties. 'Culture', on the other hand, denotes the subjective and relative world that is devoid of objectivity. It is "something artificial which only becomes constructible by bracketing out nature"[10]. In modern society, it includes religion, faith and its variants (e.g. spirituality), and is not a constituent of natural sciences.

Although there are no explicit references to this framework in the minutes of the meetings, the council members did not voice any clear opposition to this framework either. This suggests that the dichotomy between nature and culture was a shared knowledge among the committee members. That is, the meanings of the comments were 'understood' when each comment was perceived through this framework. For instance, one of the council members made the following comment on spirituality:

I think the English word 'spirit' can be translated in a number of ways, but fundamentally speaking, ifyou broadly group these meanings you have the 'mystical' and that related to the 'soul'. When Lindbergh flew across the Atlantic, he named his aircraft 'Spirit of St. Louis'. It can also bring to mind the 'Japanese spirit (Yamato-Damashii)'. But what I've been asking Mr. Kato and Mr. Kimura since a short while ago is that, in terms of the definition of health, are we saying that 'spiritual' would be included along with 'mental' to form an essential whole? If so, then it would mean that those who are not spiritual are not healthy. I want some clarification on this.

This comment was rooted in the view that 'spiritual' belongs to the realm of 'culture' while 'mental' belongs to the realm of 'nature'. In other words, the council me mber felt that spirituality should not be included within the definition of 'health' because he perceived 'health' as a matter that only belonged to the realm of 'nature'. The above point was developed further with the following argument from another council member:

When thinking about health and medical care or when thinking about human existence...there is really no such thing as a person without a spirit. If you accept someone's existence as human-irrespective of whether or not you're speaking in religious terms - as long as someone exists as a human, they have a spirit. This position should form the premise. The idea that human beings have a spiritual existence is the context for this...I believe that the fundamental position is that spirituality exists within each and every human being.

This comment is also based on the modern view that recognizes the realms 'nature' and 'culture' in human existence. However, unlike the earlier one, this comment seeks to assert that 'health' is related to 'culture' and not separated fro $m$ it.

\subsection{Perceiving 'Health'}

Three broad lines of argument could be identified in the responses to the question of whether 'health' belongs within the realm of 'nature' or 'culture'. First, three committee members supported the first argument that 'health' only belongs within the realm of 'nature' and falls within the purview of medical science. Second, two committee members believed that the answer to whether 'health' belongs to the realm of 'culture' is dependent on historical and social constructs. Finally, four committee members argued that 'health' does belong to the realm of 'culture'.

Criticizing the move to include 'spirituality' with in the definition of 'health', the first group of co mmittee members explained that the term 'spirituality' did not apply to the natural sciences. They viewed 'health' as 'a question of science' and considered 'spirituality' on par with physical and mental states: 
This[the question of whether or not to include 'spirituality' within 'health'] is not fundamentally a question of how it [spirituality] should be translated. To begin with, it has been grouped with the word 'mental', and I also have a problem with the whole idea of adding spirituality in the definition of 'health' itself .... Making a common sense judgement on the issue, I would say that including spirituality as an essential component of 'health' is just not right. This[health] is a question of science.

They also argued that only med ical doctors can ascertain a person's health and that the definition should not prevent doctors from making this judgement:

In medical care, the word 'health' is already used in a variety of contexts. If we do this [add a 'spiritual' dimension to 'health'] I feel that it will lead to many problems and much confusion. For example, iflanguage such as spiritual, religious or incorporeal is included in the definition of health, then judgements will be very difficult to make... and then you have health status reports carried out for employment and the like and you get the same thing with university entrance exams... I'm concerned that doctors will end up being unable to write such reports using their own judgement.

Two committee members argued that the question of inclusion of 'spirituality' in 'health' depended on the relationship between the state and religion as well as between science and religion. In states that have adopted a religion, 'health' is included within the do main of 'culture'. The following comment illustrates this argument:

Take, for example, the case of Islam. The idea of clearly separating politics and religion or clearly separating the activities of the state and the activities of religion is much more of a Christian way of thinking. When it comes to Islam, the idea of seeing the activities of the state and the activities of religion or secular activities and religious activities as part of a whole is very deep rooted. Therefore, if you approach this issue from an Islamic point of view, you have, in a sense, a religious outlook where religiosity and secularity are so closely knit that you could even say that a concept of 'health' that excludes religiosity is in fact not even health in the true sense.

This view suggests that differences in the definition of health could be based on the relig ious and political beliefs of countries. For instance, while contemporary Christian states distinguish between politics and religion, Islamic states do not follow this practice. As a result, in Islamic states, a definition of 'health' that is devoid of spirituality would be unacceptable. In fact, even in Christian states until the mid-nineteenth century, the notion of spirituality was embedded in concept of 'health', as suggested in the comment below:

With regard to the idea including 'spiritual' in relation to 'mental'... In traditional medicine, there was hardly any difference between the religious concept of 'healing' and the objective concept of 'medical treatment', for example, the concept of 'health' as an assessment of preventive effects....Speaking in terms of cultural history, even in
Europe, the concept of 'health' and the religious concept of 'healing' were closely linked up until the mid-nineteenth century.

This comment indicates that the subject of health and spirituality is also dependent on history. With regard to historical relativity, committee members also stated that 'in the past, the prevailing attitude in medical care and science contained, in a sense, a subjective element that aimed to view human nature as a whole'; however, with the development of science and increase in environmental dangers, 'there has been a shift towards a more negative as well as more objective view that seeks to identify such latent dangers against "health"'. Moreover, in the course of development, modern medical science has also rid itself of all aspects that belonged to the realm of 'culture'.

If you think about the significance of adding this [spirituality] to the definition of 'health', on the positive side, ifyou perceive 'health' as an individualistic way of life and well-being in every sense of the word, incorporating 'spirituality' within 'health' has great significance. However, in the process evolution... modern medical science evolved by eliminating the spiritual aspects of health...

Four committee members argued that 'health' is related to the realm of 'culture'. In support of this argument, a member opined that the notion of spirit is synonymous with human existence and that the concept of healing includes a religious dimension. The member also said that there are aspects to 'health' that cannot be classified on the bas is of mental and physical perspectives and relate to the realm of 'culture' at large and spirituality in particular. In light of the widespread deliberations on spirituality at the international level, the Council members wanted Japan to play an active role in furthering the dialogue on the relationship between 'health' and spirituality:

It's not only in the field of health, but also in the economic development plans of the World Bank ... the question of spirituality and the question of economic development in developing countries - such questions were issues were not addressed in the past, but they now represent an emerging theme. Within Islamic societies in particular, health and spirituality will become an even greater issue in the future and this issue will crop up not only in connection with health but also in connection with economic or developmental issues... and in particular with ideas such as Health For All In The Year 2000 (W.H.O). We are in an age where our lives are connected with the rest of the world and this world is looking to consider spirituality anew. The world as it is now has presented us with a challenge and how we respond to it is vital. If 'we are who we are', irrespective of the external changes, Japan will become more and more isolated and will not be able sustain its foothold as a member of the international community....

Comments were also made to support the view that 'health' is not only a subject of science (medical science):

Whether a person is healthy or not will be established according to how spirituality is translated[into medical terms]. The term 'spiritual' must not be understood as faith 
or inspiration. The term 'mental' is associated with psychiatrists while the term 'spirit' refers to things like will and morale. One should question whether these are in the right shape... Therefore 'mental' faculties can be evaluated medically, but issues of the heart and soul, which must be judged in the social context, are worldwide issues. This means that the word 'spirit' is a significant issue.

\subsection{Link between Commi ttee Members' Position on the Proposal and Their Area of Expertise}

It is likely that committee's members varying responses to 'health', 'spirituality' and whether 'spirituality' should be added to the WHO's 'definition of health' were influenced by different factors. To explore if their do mains of expertise had an effect on the council's final decision to reject the proposal, the study explored the correlation between the content of each committee member's comments and his or her field of expert ise.

Of 18 members whose academic expertise lay in the field of natural sciences, six members $(33.4 \%)$ offered comments on how to perceive 'health'. Not only did they offer different perspectives on health, their stand on the proposal to include spirituality also varied (Table 2). However, of the five members who opposed the proposal to include 'spirituality' in the WHO's 'definition of health', four specialized in medical science.

All the three committee members specializing in non-science fields felt that 'health' was embedded in the realm of 'culture'. However, their stand on the proposal depended on whether or not they perceived 'health' as historically and socially relative. Surprisingly, me mbers who perceived health as being historically and culturally relative were against the proposal. This was because they believed that the WHO definition of 'health' should be based on objective standards and that identifying the minimum standards for 'health' would be beneficial for the citizens of developing countries. The following comment expresses this view:

In the so-called developing world in particular ... a concept of 'health' that includes a higher class of spirituality will give rise to the idea that scientific concepts of 'health' are insufficient, and there is a possibility that this will lead to, in a sense, rather risky outcomes. I would say that using a slightly more objective standard as the international yardstick would be profitable in a number of ways.

Members also voiced the concern that physical and mental care may be compromised as a result of including spirituality:

One of the problems you'd face if you added spirituality would be the possibility that medical care and healing needs, in a certain sense of the word, would be considered fulfilled as long as attention is paid to the aspect of spirituality even if it implies insufficient mental and physical care... If 'medical care' is defined as something that aims to restore health and then 'health' contains 'spiritual' in its definition, then that is indeed a possibility.

Table 2. Analysis of the comments make by members across three deliberation meet ing( $\mathrm{N}=21)$

\begin{tabular}{ccccc}
\hline & \multicolumn{2}{c}{ Natural Sciences } & \multicolumn{2}{c}{ Non-Life Sciences } \\
\hline Overall & $18(13)$ & $100.0 \%(72.2 \%)$ & 3 & $100.00 \%$ \\
\hline Made comments & $9(6)$ & $50.0 \%(33.3 \%)$ & 3 & $100.00 \%$ \\
No comments & $9(7)$ & $50.0 \%(38.9 \%)$ & 0 & $0.00 \%$ \\
\hline Made comments & Definition of spirituality & & $100.00 \%$ \\
No comments & $6(5)$ & $33.3 \%(27.8 \%)$ & 3 & $0.00 \%$ \\
\hline
\end{tabular}

Which part of human existence 'health' relates to

\begin{tabular}{ccccc}
\hline $\begin{array}{c}\text { Made comments } \\
\text { Related to realm of 'nature' only }\end{array}$ & $3(3)$ & $16.7 \%(16.7 \%)$ & 0 & $0.00 \%$ \\
$\begin{array}{c}\text { Is historically and socially } \\
\text { denendent }\end{array}$ & $1(1)$ & $5.6 \%(5.6 \%)$ & 1 & $33.30 \%$ \\
Also related to realm of 'culture' & $2(1)$ & $11.1 \%(5.6 \%)$ & 2 & $66.70 \%$ \\
No comments & $12(8)$ & $66.7 \%(44.4 \%)$ & 0 & $0.00 \%$ \\
\hline Whether spirituality should be added to WHO's 'definition of health' & \\
\hline Should be added & $2(0)$ & $11.1 \%(0.0 \%)$ & 1 & $33.30 \%$ \\
Should not be added & $5(4)$ & $27.8 \%(22.2 \%)$ & 1 & $33.30 \%$ \\
No comments & $11(9)$ & $61.1 \%(50.0 \%)$ & 1 & $33.30 \%$ \\
\hline
\end{tabular}




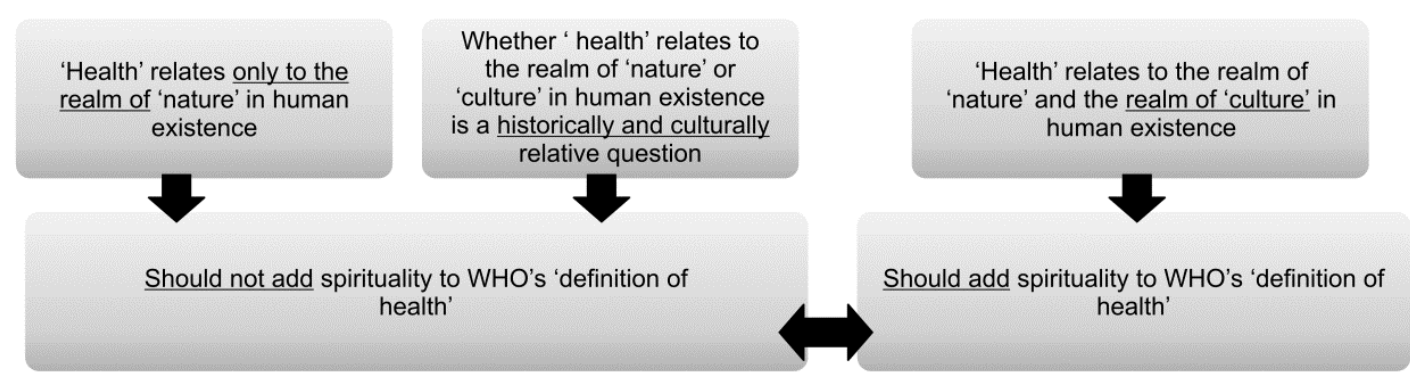

Figure 1. Relation between whether or not spirituality should be added to WHO's 'definition of health' and fixed idea of 'health'

Thus, even members that acknowledged the spiritual aspects of 'health' were not in favor of including 'spirituality' in the WHO defin ition because they believed that the WHO 'definition of health' should represent the minimum standards to be met by all countries around the world. Only two members were in the favor, arguing that 'health' includes the realm of 'culture', which is shaped by the society and time. Their assertion is in agreement with the view that health care, which involves making judgments on 'health', is not only exclusively under the jurisdiction of med ical science or doctors who study it. The three dominant views exp ressed by different members are shown in Figure 1.

It is interesting to note that most of the members who unanimously decided to exclude 'spirituality' from the WHO definition belonged to the field of medicine. In fact, Eiichi Nakamura, who represented Japan at the subcommittee meeting that decided against discussing the proposal at the WHA52, also specialized in the field of natural sciences. Predictably, the council members who supported the proposal to amend the WHO definition of health were from non-medical fields. Thus, it appears that domain expertise exerted a moderate influence over council me mbers' position on the proposal.

\section{Discussion: The Positioning of Spirituality in WHO's 'Definition of Health' and the Challenges Involved}

Members of the Health Science Council held different views on 'spirituality' and how it was positioned in the definition of health and disease. First, those who perceived 'health' as belonging exclusively to the realm of 'nature' were medical scientists. They believed that 'health' is a subject of science (medical science) and that only medical doctors are suited to offer judgments on its state[11]. Second, the committee members who believed that history and society influenced the question of 'health' belonging to the realm of 'culture' also comprised medical scientists. While these members recognized the spiritual aspects of health, they were not in favor of adding 'spirituality' to the definition of health. Lastly, the group who felt that 'culture' is universally embedded in the 'definition of health' did not consist of medical scientists. This group not only supported the proposal to add 'spirituality' to the defin ition of health but also believed that the subject of modern health care and spirituality required careful deliberation. It is reasonable to consider that the discrepancy in the views on the proposal could be attributed to whether members perceived 'health' (1) as something that belongs exclusively to the realm of 'nature', (2) as a component of culture that is influenced by history and society, or (3) as universally belonging to the realm of 'culture' (Figure 1).

An analysis of the number of comments vis-à-vis the number of attendees at the three deliberation meetings of the Health Science Council offers interesting insights. Of the total 21 committee members, nine members did not comment on the issue (Table 2). Most of them were experts in the natural sciences, and seven out of nine were medical scientists. Of the nine experts in the natural sciences who commented on the subject, six spoke about the defin ition of spirituality, seven discussed the relationship between areas of human existence and 'health', and six members exp ressed their opinions on whether or not 'spirituality' should be added to the definition of health. All three experts who did not belong to the fields of natural sciences commented on both the definition of spirituality and the relationship between the areas of human existence and 'health'. Two of these members shared their views on the proposal.

Members whose area of expertise lay in the natural sciences offered fewer comments and personal opinions than experts from outside the natural sciences. In particular, there was a scarcity of comments from medical scientists on topic of human existence and 'health'. Why did some members who participated in the meetingsdid not comment? The answer could possibly lie in the challenges that medical scientists face in speaking positively about 'health'. Clinically diagnosed diseases, their symptoms, and treatments are well known to the medical fraternity, and experts from the field of medicine can usually speak eloquently on such matters. However, 'health' represents an absence of these diseases and is possibly viewed as a residual concept. Therefore, it is likely in contexts where 'health' is defined as something positive, medical experts lack the vocabulary to express the views.

'Health' is also a normative concept that is amendable[11] and continues to undergo changes[12]. For medical scientists, 'health' is a normative model used to biologically evaluate whether a physical or mental condition is normal or pathologic. On the other hand, people can lead 'healthy' lives even while suffering from disease or disability. 
Canguilhem[13] explains that a person who has adopted a normative model of living is beyond normal in that he or she responds adequately to his or her environment. Thus, the concept of 'health' is dynamic and varies according to time, society, and individual values. Hence, it is not possible to view 'health' as belonging to the realm of 'nature' a lone.

The WHO definition of health has not been revised and the necessity of a revision was not recognized in the discussions that took place in the Ministry of Health, Labour and Welfare, which has jurisdiction over Japan's health care system and the health of Japanese citizens. In spite of this, there have been increasing number of textbooks in Japan on health care, nursing care, and welfare that discuss the presence of a spiritual dimension in 'health'.

When viewed as a dynamic concept, 'health' is not only a reflection of individual values but also an outcome of the juxtaposition of people's diverse values. This concept of 'health' possibly explains the conflicting views of the members of the Health Science Council and Japan's subsequent decision to postpone deliberations on including 'spirituality' as a dimension of health. The process whereby the members agreed to disagree on the proposal is surely an accurate reflection of the challenges involved in debating the position of 'spirituality' and in the process whereby 'health' is interpreted as a dynamic concept through linguistic activities and dialogue.

\section{Conclusions}

Although the Japanese people do not generally have a sense of affiliation to any specific religious organization, they do hold in common a deep reverence towards forces that transcend human understanding. On the other hand, modern medicine has developed outside the domain of spirituality. This relates to the fact that modern science developed with a clear separation between 'nature' and 'culture'. In recent years, there has been an increasing interest towards spirituality in health care settings throughout Japan and the concept of spiritual health is also being discussed. However, medical doctors who contributed to the discussion on the WHO 'definition of health' argued that the concept of 'health' belongs to the domain of natural science and should be kept apart from the domain of culture. In other words, in order to define health as a whole concept rather than as a framework in modern science, there needs to be a paradigm shift amongst medical scientists and other natural scientists so that 'health' can be considered separately from the issue on 'the presence or absence of disease'.

\section{ACKNOWLEDGEMENTS}

I am extremely grateful to Professor Koichiro Kuroda of Ryukoku University, School of sociology, Shiga for his valuable advice. In addition, I would also like to thank the members of the study group of the sociology of medicine, and health and illness.

\section{REFERENCES}

[1] Masako Nagase, Trends in discussions about health in medical care and nursing-An analysis of articles related to spirituality compiled by the Japan medical abstracts society, Bulletin of the Faculty of Sociology, no.29, pp.50-65, Ruyukoku University, Japan, 2006.

[2] Ministry of Health, Labour and Welfare, Press release data on what follows after the proposal to revise the 'definition of health' in the WHO Charter-Results of 52nd WHO General Meeting. Online Available: http://www 1.mhlw.go.jp/houdou/ 1110/h1026-1_6.html (accessed 21 December 2010).

[3] YomiyuriShimbun, What is the religious view of the Japanese? Series of opinion polls, 29 May 2008.

[4] KanUsuda, Hidehiko Tamashiro, Koichi Kono,"How a revision to the 'definition of health' was not agreed upon", Japanes e Journal of Public Health, vol.47, no.12,pp.1013$1017,2000$.

[5] Kiichiro Tsutani., AsakoKusama.,"A spiritual dimension of health in WHO's 'View of Health'-National delegates' statements",Toy ou Medical,vol.8, no.6, pp.90-92, 2000.

[6] Masakazu Tanatsugu,"What can be seen in the issues of the definition of 'health' in the WHO Charter-Spirituality, medical science and religion", Journal of Kyoto Prefectural University of Medicine,vol. 112, no.9, pp.651-661, 2003.

[7] Hiroyuki Eto,"The essence of spiritual as distin guished from mental - the issues presented by the proposal to revise 'health' in the WHO Charter", Quality Nursing,vol.10, no.12, pp.5967, 2004.

[8] John Lofland and Lyn H Lofland, Analyzing Social Settings: A Guide to Qualitative Observation and Analy sis, Wadsworth Publishing, Belmont, CA, 1995.

[9] IkuyaSato, Qualitative Data Analysis-Principles, Methods and Practice, Shin-yo-sha, Tokyo, 2008.

[10] Bruno Latour, Nous N'avonsJamaisEteModernes: Essaid' anthropologie Syme-trique, Shin-hy ousya, Tokyo, 2008.

[11] Junichi Sato, Medical science. In: KoichiroKuroda (ed), Social Studies in Modern Medical Science-Japan's Current Situation and Issues, Sekaishiso-sha, Kyoto, pp.2-35, 1999.

[12] Mildred Blaxter, Health, Polity Press, Cambridge, 2004.

[13] GeorgesCanguilhem, Le Normal et le Pathologique, P.U.F, Paris, 1966. 